\title{
Urinary symptoms: prevalence and severity in British men aged 55 and over
}

\author{
D J W Hunter, C M McKee, N A Black, C F B Sanderson
}

\begin{abstract}
Objective - To measure the prevalence and severity of urinary symptoms among men aged 55 and over in the British population. Design - Cross sectional population survey using a postal questionnaire.

Setting - North West Thames health region.

Subjects -1480 men aged 55 years and over randomly selected from 8 general practices.

Main outcome measures - Self reported frequency and severity of urinary symptoms, their bothersomeness and previous prostate surgery.

Results - The response rate among eligible subjects was $78 \%$. The prevalence of moderate and severe symptoms was 204 per 1000 , rising from 160 per 1000 in the 55-59 age group to 259 per 1000 in the $70-74$ age group and declining after the age of 80 to 119 per thousand in the $85+$ age group. Twelve per cent of men reported previous prostate surgery, and the probability of having had surgery increases steadily with age. About a third of those undergoing surgery have recurrence or persistence of symptoms after surgery. Of men with moderate and severe symptoms, $27.9 \%$ reported that their symptoms were a medium or big problem, $36.9 \%$ reported that their symptoms interfered with their daily activities at least some of the time, and $43.1 \%$ were unhappy or 'felt terrible' about the prospect of a future with their current symptoms.

Conclusion - The prevalence of urinary symptoms in men is lower than previously reported, although there is a substantial number of men who are bothered by, or who find their lives adversely effected by them.
\end{abstract}

(f Epidemiol Community Health 1994;48:569-575)

Health Services Research Unit, Department of Public Health and Policy, London School of Hygiene and Tropical Medicine, Keppel St, London WC1E 7HT

D J W Hunter

C M McKee

C M McK

C F B Sanderson

Correspondence to: Dr D J W Hunter.

Accepted for publication January 1994

Benign prostatic hyperplasia is the commonest cause of urinary symptoms affecting middle aged and elderly men. It is becoming an increasing challenge to the health service because of an aging population and the introduction of new forms of treatment. Knowledge of the prevalence of urinary symptoms and their impact on men form the basis of the three measures required by those involved in the planning and provision of services for benign prostatic hyperplasia: the number of men in the population experiencing urinary symptoms that bother them (felt need); the number of men with symptoms who seek treatment (demand); and the number of men considered by surgeons to be in need of treatment, based on both men's urinary symptoms and on clinical findings (normative need).

Estimates of the prevalence of urinary symptoms among men vary widely. In general health surveys of men over the age of 65 , between 16 and $40 \%$ report having either urinary symptoms or a previous prostatectomy, or both (Spain $16 \%$; USA $25 \%$; Israel $40 \%$ ). ${ }^{1-3} \mathrm{~A}$ household survey undertaken in Michigan in 1983-84 found that $35 \%$ of men over the age of 60 had one or more symptoms of prostatism. ${ }^{4}$ A review of general practice case notes in the UK suggested that $6 \%$ of men over the age of 60 had undisclosed 'marked prostatism', based on the presence of four urinary symptoms, and a further $14 \%$ had 'mild prostatism', with three symptoms. ${ }^{5}$ In a questionnaire administered to men over the age of 60 who attended a health screening clinic in the UK, $18 \%$ reported five or more urinary symptoms. ${ }^{6}$ A recent study, defining benign prostatic hyperplasia using a combination of urinary symptoms, flow rates, and prostatic size, reported a prevalence among Scottish men aged 40 to 79 of 253 per $1000 .^{7}$ A virtually identical study in the USA found that prostatism rose from $26 \%$ in the $40-49$ age group to $46 \%$ in $70+$ age group, higher than the prevalence found in the Scottish study. ${ }^{8}$

These studies are not sufficient to assess the 'felt need'. They provide little information on the severity of symptoms and do not measure the extent to which men are bothered by their symptoms. The latter point is important as it has been suggested that a third of men with mild symptoms may not want treatment. ${ }^{9}$ This paper describes a survey of felt need for treatment of benign prostatic hyperplasia in the UK that addresses these issues. A subsequent paper will report on the relationship between the prevalence of urinary symptoms and demand for treatment.

\section{Methods}


Table 1 Demographic characteristics of responders, urinary symptom prevalence survey, North West Thames health region, 1992

\begin{tabular}{|c|c|c|}
\hline & Sample (\%) & Population (\%) \\
\hline $\begin{array}{l}\text { Age group (y): } \\
55-59 \\
60-64 \\
65-69 \\
70-74 \\
75-79 \\
80-84 \\
85+\end{array}$ & $\begin{aligned} 275 & (19) \\
322 & (22) \\
298 & (21) \\
236 & (16) \\
157 & (11) \\
104 & (7) \\
51 & (4)\end{aligned}$ & $\begin{array}{lll}89 & 073 & (24) \\
80 & 261 & (22) \\
68 & 962 & (19) \\
51 & 837 & (14) \\
41 & 059 & (11) \\
23 & 932 & (6) \\
13 & 437 & (4)\end{array}$ \\
\hline Total & $1443(100)$ & $368561(100)$ \\
\hline $\begin{array}{l}\text { Ethnicity (>55 y) } \\
\text { White } \\
\text { Non-white } \\
\text { Total }\end{array}$ & $\begin{array}{r}1389(97) \\
40(3) \\
1429(100)\end{array}$ & $\begin{array}{rrr}345756 & (92) \\
30829 & (8) \\
376 & 585 & (100)\end{array}$ \\
\hline
\end{tabular}

Notes on table: (1) Missing data are not included in column totals. (2) Population estimates for North West Regional Health Authority are taken from the OPCS 1991 Census, Count
Monitors.

review. Seven practices withdraw at this stage. The remaining eight practices were distributed throughout the region and included inner city, suburban, and rural practices. These practices were asked to provide a list of all men aged 55 years and over. In total, 3716 men were identified, with the number in each practice ranging from 143 to 1180 . With the exception of the smallest practice, where the entire list was used, 265 men were randomly sampled from the whole of each practice's list to create a database of 2000 names and addresses. This number was chosen to yield $95 \%$ confidence intervals of $\pm 1.5 \%$ if the true prevalence of moderate or severe symptoms was around $25 \%$.

A two page questionnaire, together with a personally addressed covering letter from the individual's general practitioner and a stamped, addressed envelope for reply, were sent to each man. Non-responders were sent a reminder letter and a second questionnaire one month later. The questionnaire sought information about the men's sociodemographic characteristics (age and ethnicity) and any urinary symptoms they had experienced over the preceding month. Questions on urinary symptoms were taken from the recently published American Urological Association (AUA) symptom index,${ }^{11}$ with some minor modifications to the wording of the questions to make them more appropriate to a British population. For example, the AUA question on fullness 'Over the past month or so, how often have you had a sensation of not emptying your bladder completely after you finished urinating?' was changed to 'In the past month, how often did you feel that your bladder did not empty fully after urinating?'. A pilot version of the questionnaire, sent to 30 men selected from a general practice in the North East Thames region, achieved a response rate of $80 \%$ and led to minor modifications in the layout of the questions. For comparison, population estimates and demographic information for residents of North West Thames region were obtained from the 1991 census. ${ }^{12}$ Ethical approval was sought and obtained from the relevant district ethics committees.

To investigate the possible effects of response bias, general practice case notes from 100 randomly selected non-responders were compared with the case notes of 100 randomly selected responders. Information taken from these case notes included age, history of urinary symptoms, previous prostate surgery, and medical history. Reasons for the unavailability of any case notes, such as the patient having died or moved away, were recorded.

A symptom index, ranging from 0 to 30 , was calculated by summing the scores of six urinary symptoms (fullness, frequency, intermittency, urgency, poor flow, and hesitancy) where each symptom was assigned one of the following values: never $=0$, hardly ever $=1$, less than half the time $=2$, about half the time $=3$, more than half the time $=4$, and almost always $=5$. Unlike the AUA-7 symptom index, nocturia was not included in our symptom index for three reasons: (a) it has many causes other than urinary tract disorders, such as cardiovascular disease and the person's fluid intake before going to bed, and is the symptom that responds least well to prostatectomy; $;^{13}$ (b) in a validation study of the AUA index, the highest intersymptom correlation was between nocturia and frequency, and frequency was already included in the index; and (c) the categories of nocturia severity we obtained were too crude to use. The symptom index was categorised into four levels of severity; none (0), very mild (1), mild (2-9), moderate (10-18), and severe (19-30). These cut off points were consistent with those used in a cohort study of men undergoing prostatectomy in Oxford and North West Thames region. ${ }^{13}$

Data analysis consisted of frequency distributions. Confidence intervals for proportions were calculated at the $95 \%$ level using the method of Fleiss. ${ }^{14}$ Patterns of symptoms and surgical status based on age by individual years were smoothed using five point moving averages.

Table 2 Characteristics of responders and non-responders, urinary symptom prevalence survey, North West Thames health region, 1992

\begin{tabular}{|c|c|c|c|}
\hline & Responders & Non-responders & $\begin{array}{l}\text { Standard error of } \\
\text { the difference }\end{array}$ \\
\hline Mean age (y): & 70 & 71 & \\
\hline $\begin{array}{l}\text { Status (no }(\%)) \text { : } \\
\text { On GP list } \\
\text { Decreased/moved/ghost } \\
\text { Notes not found }\end{array}$ & $\begin{array}{rc}98 & (98) \\
0 & (0) \\
2 & (2)\end{array}$ & $\begin{array}{rr}81 & (81) \\
8 & (8) \\
11 & (11)\end{array}$ & $\begin{array}{l}4 \cdot 17^{* *} \\
2 \cdot 71^{* *} \\
3 \cdot 43^{* *}\end{array}$ \\
\hline Total & $100(100)$ & $100(100)$ & \\
\hline $\begin{array}{l}\text { Urinary symptoms (no (\%)): } \\
\text { No urinary symptoms } \\
\text { Previous prostate surgery } \\
\text { Urinary symptoms } \\
\text { Urinary symptom, referral } \\
\text { Other urology }\end{array}$ & $\begin{array}{rr}79 & (81) \\
7 & (7) \\
5 & (5) \\
4 & (4) \\
3 & (3)\end{array}$ & $\begin{array}{rr}72 & (89) \\
1 & (1) \\
4 & (5) \\
2 & (2) \\
2 & (2)\end{array}$ & $\begin{array}{l}5 \cdot 33 \\
2 \cdot 80^{*} \\
3 \cdot 92 \\
2 \cdot 50 \\
2 \cdot 31\end{array}$ \\
\hline Total & $98(100)$ & $81(100)$ & \\
\hline
\end{tabular}



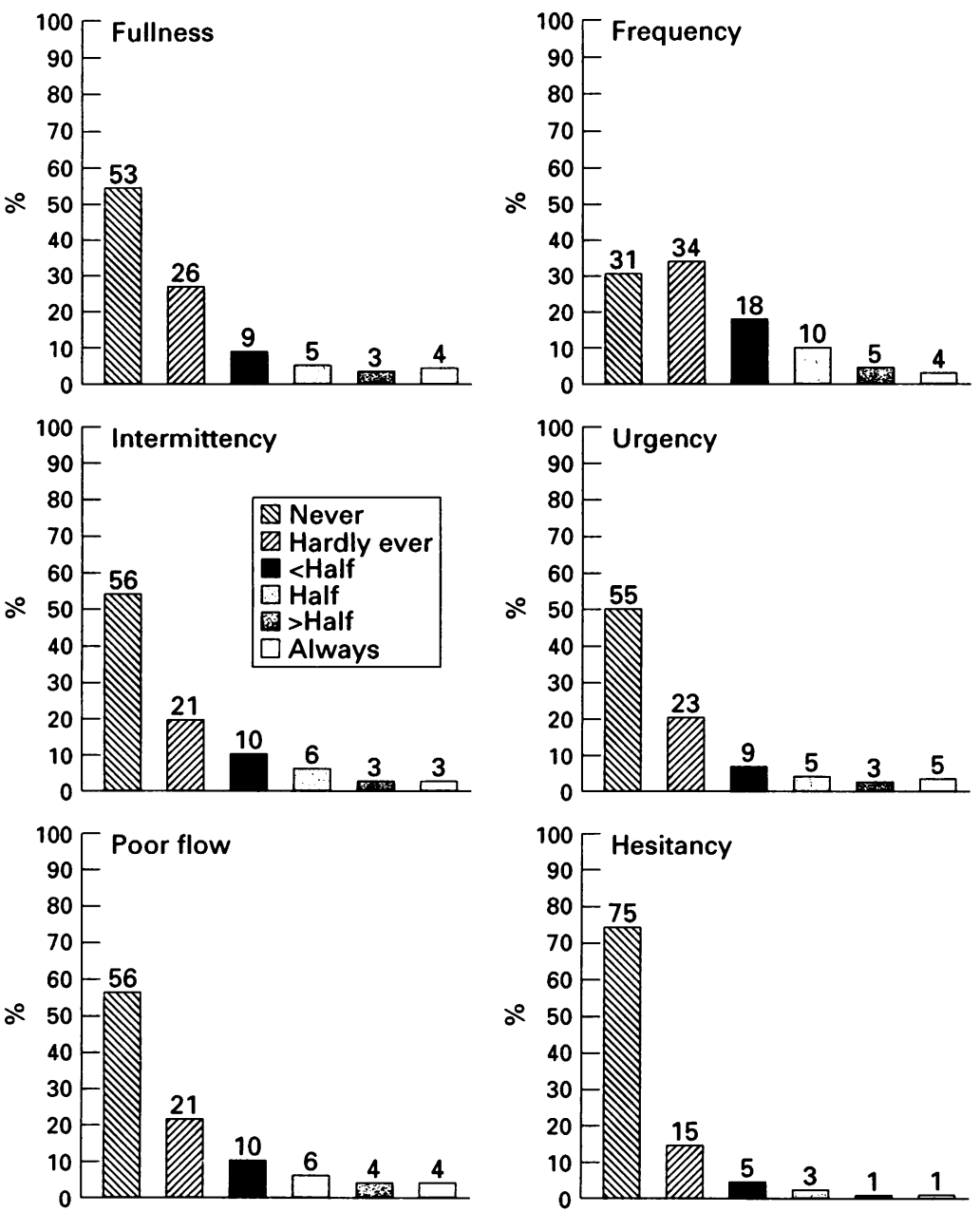

Figure 1 Distribution of urinary symptoms, men aged 55 years and over in North Thames health region.

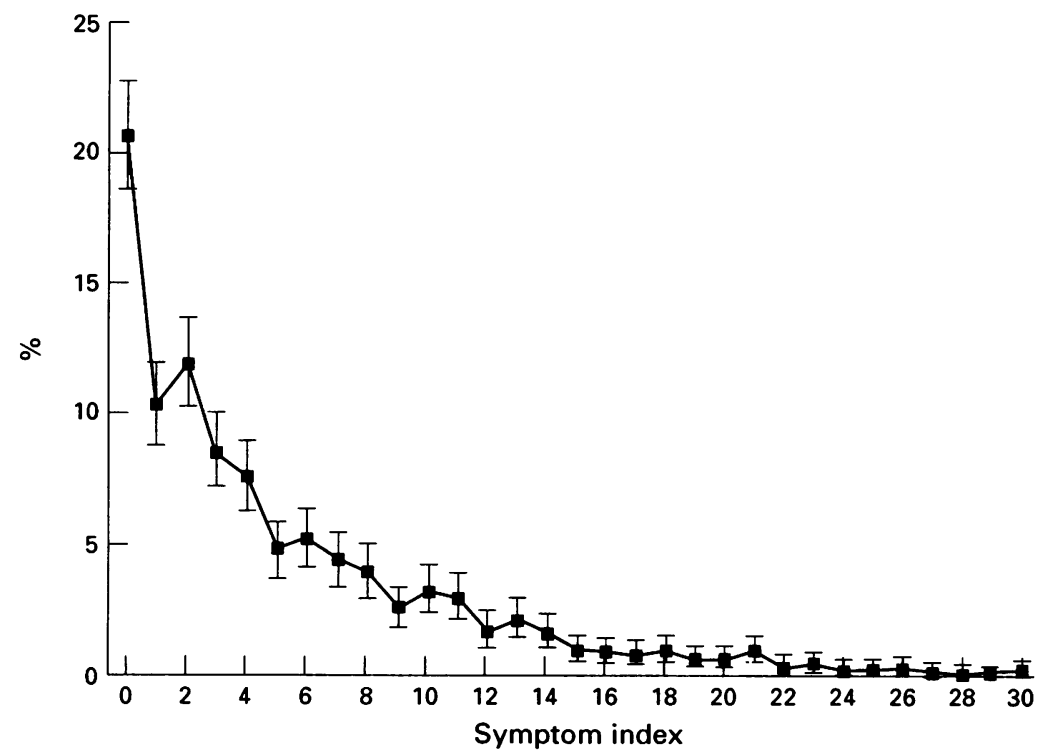

Figure 2 Distribution of symptom index (95\% CI) in men aged 55 years and over in North Thames health region, 1992. tionnaires) after a postal reminder. The age structure of those responding was similar to that of all men living in North West Thames region, except for those in the 55 to 59 age group, who seemed to be under-represented in our sample (table 1). Responders were more likely to be white than would be expected from the male population in this age group.

The comparison of subsamples of responders and non-responders (table 2) found no difference in mean age. Apparent non-responders included $8 \%$ who had either died or moved or for whom the general practitioner had no evidence of a medical record. In addition, for $2 \%$ of responders and $11 \%$ of non-responders, although there was evidence that a record existed, these records could not be located. Comparison of the medical records available showed that responders were more likely to have undergone previous prostate surgery $(7 \% v 1 \%$; $\mathrm{p}<0.05)$, but there was no significant difference in their medical histories of urinary symptoms.

\section{PREVALENCE AND SEVERITY OF SYMPTOMS}

The distribution of each urinary symptom in relation to the level of severity is shown in figure 1. Most men report that they never, or hardly ever, experience these symptoms. The distribution of the symptom index is also strongly skewed to the left (fig 2); few men experience high composite symptom scores. On categorising the data, $20.8 \%$ report no symptoms, $10.4 \%$ very mild symptoms, and $48.5 \%$ mild symptoms (table 3 ). The overall proportion of men with moderate/severe symptoms was $20 \cdot 4 \%$. This increased from $16 \cdot 2 \%$ in those aged 50 to 59 years to a plateau of between 20 and $25 \%$ in the age group between 65 and 79 . It then fell to $11.9 \%$ in the over 85 s.

\section{MPACT OF SYMPTOMS}

The extent to which men were bothered by their symptoms increased significantly with increasing symptom severity (table 4 ). Of those with very mild and mild symptoms, only $0.5 \%$ felt they were a medium or big problem; this increased to $15.9 \%$ of those with moderate symptoms and $66.2 \%$ of those with severe symptoms. Of those with moderate symptoms, $2.8 \%$ reported interference in their daily activities most or all of the time (table 5). This increased to $17.9 \%$ for those with severe symptoms. When asked about spending the rest of their life with their current symptoms, $11 \%$ of men reported they would feel unhappy or terrible (table 6). This proportion varied in relation to symptom severity from $3.5 \%$ of those with very mild and mild symptoms to $76.4 \%$ with severe symptoms.

\section{Results}

CHARACTERISTICS OF THE SAMPLE

Of the 2000 men who were sent a questionnaire, 21 had died and 74 were unknown at the address in the general practice records, so that the final study population was 1905 . The response rate after the first mailing was $64 \%$, rising to $78 \%$ (1480 returned ques-

\section{PREVIOUS PROSTATE SURGERY AND OTHER} UROLOGICAL SYMPTOMS

The prevalence of urinary symptoms will partly depend on prostatectomy rates in the past and the effectiveness of this surgery. Altogether 164 $(12 \%)$ men reported having undergone previous prostate surgery (table 7 ). To allow for 
Table 3 Frequency distribution of symptom severity in relation to age group in men aged 55 and over, North West Thames health region, 1992

\begin{tabular}{|c|c|c|c|c|c|c|c|c|}
\hline \multirow[b]{2}{*}{$\begin{array}{l}\text { Age group } \\
\text { (years) }\end{array}$} & \multicolumn{5}{|c|}{ Symptom severity } & \multirow[b]{2}{*}{$\begin{array}{l}\text { Total } \\
\text { No (\%) }\end{array}$} & \multirow[b]{2}{*}{$\begin{array}{l}\text { Moderate } \mathcal{G} \text { severe } \\
\text { combined } \\
\text { No (\%) }\end{array}$} & \multirow[b]{2}{*}{$\begin{array}{l}(95 \% \text { CI of } \% \\
\text { moderate } \mathcal{E} \text { severe) }\end{array}$} \\
\hline & $\begin{array}{l}\text { None } \\
\text { No (\%) }\end{array}$ & $\begin{array}{l}\text { Very mild } \\
\text { No (\%) }\end{array}$ & $\begin{array}{l}\text { Mild } \\
\text { No (\%) }\end{array}$ & $\begin{array}{l}\text { Moderate } \\
\text { No (\%) }\end{array}$ & $\begin{array}{l}\text { Severe } \\
\text { No (\%) }\end{array}$ & & & \\
\hline $\begin{array}{l}55-59 \\
60-64 \\
65-69 \\
70-74 \\
75-79 \\
80-84 \\
85+\end{array}$ & $\begin{array}{l}57(21 \cdot 0) \\
72(23 \cdot 2) \\
63(22 \cdot 0) \\
43(18 \cdot 9) \\
30(20 \cdot 3) \\
12(12 \cdot 8) \\
10(23 \cdot 8)\end{array}$ & $\begin{array}{c}32(11 \cdot 8) \\
34(11 \cdot 0) \\
30(10 \cdot 5) \\
22(9 \cdot 7) \\
11(7 \cdot 4) \\
10(10 \cdot 6) \\
4(9 \cdot 5)\end{array}$ & $\begin{array}{l}139(51 \cdot 1) \\
144(46 \cdot 6) \\
134(46 \cdot 7) \\
104(45 \cdot 8) \\
77(52 \cdot 0) \\
48(51 \cdot 1) \\
23(54 \cdot 7)\end{array}$ & $\begin{array}{r}35(12 \cdot 8) \\
49(15 \cdot 8) \\
49(17 \cdot 1) \\
38(16 \cdot 7) \\
22(14 \cdot 9) \\
18(19 \cdot 2) \\
5(11 \cdot 9)\end{array}$ & $\begin{aligned} 9(3 \cdot 3) \\
11(3 \cdot 6) \\
11(3 \cdot 8) \\
21(9 \cdot 2) \\
8(5 \cdot 4) \\
6(6 \cdot 4) \\
0(0)\end{aligned}$ & $\begin{array}{r}272(100) \\
310(100) \\
287(100) \\
228(100) \\
148(100) \\
94(100) \\
42(100)\end{array}$ & $\begin{array}{l}44(16 \cdot 2) \\
60(19 \cdot 4) \\
60(20 \cdot 9) \\
59(25 \cdot 9) \\
30(20 \cdot 3) \\
24(25 \cdot 5) \\
5(11 \cdot 9)\end{array}$ & $\begin{array}{c}(12 \cdot 1,20 \cdot 8) \\
(15 \cdot 2,23 \cdot 9) \\
(16 \cdot 4,25 \cdot 8) \\
(20 \cdot 4,31 \cdot 7) \\
(14 \cdot 3,27 \cdot 1) \\
(17 \cdot 3,34 \cdot 6) \\
(4 \cdot 5,23 \cdot 5)\end{array}$ \\
\hline Total & $287(20 \cdot 8)$ & $143(10.4)$ & $669(48 \cdot 5)$ & $216(15 \cdot 6)$ & $66(4 \cdot 8)$ & $1381(100)$ & $281(20 \cdot 4)$ & $(18 \cdot 3,22 \cdot 5)$ \\
\hline
\end{tabular}

$\mathrm{N}=1480,99$ missing; percentages have been rounded.

Table 4 Frequency distribution of bothersomeness in relation to symptom severity in men aged 55 and over, North West Thames health region, 1992

\begin{tabular}{|c|c|c|c|c|c|c|c|c|}
\hline \multirow[b]{2}{*}{ Bothersomeness } & \multicolumn{5}{|c|}{ Symptom severity } & \multirow[b]{2}{*}{$\begin{array}{l}\text { Total } \\
\text { No (\%) }\end{array}$} & \multirow[b]{2}{*}{$\begin{array}{l}\text { Moderate E severe } \\
\text { combined } \\
\text { No (\%) }\end{array}$} & \multirow[b]{2}{*}{$\begin{array}{l}(95 \% \text { CI of } \% \\
\text { moderate } \mathcal{E} \text { severe }\end{array}$} \\
\hline & $\begin{array}{l}\text { None } \\
\text { No (\%) }\end{array}$ & $\begin{array}{l}\text { Very mild } \\
\text { No (\%) }\end{array}$ & $\begin{array}{l}\text { Mild } \\
\text { No (\%) }\end{array}$ & $\begin{array}{l}\text { Moderate } \\
\text { No (\%) }\end{array}$ & $\begin{array}{l}\text { Severe } \\
\text { No (\%) }\end{array}$ & & & \\
\hline $\begin{array}{l}\text { No problem } \\
\text { Very small problem } \\
\text { Small problem } \\
\text { Medium problem } \\
\text { Big problem }\end{array}$ & $\begin{array}{c}290(99 \cdot 0) \\
3(1 \cdot 0) \\
0(0) \\
0(0) \\
0(0)\end{array}$ & $\begin{array}{c}142(97 \cdot 3) \\
4(2 \cdot 7) \\
0(0) \\
0(0) \\
0(0)\end{array}$ & $\begin{aligned} 509(73 \cdot 7) \\
143(20 \cdot 8) \\
34(4 \cdot 9) \\
4(0 \cdot 6) \\
0(0)\end{aligned}$ & $\begin{array}{c}44(20.5) \\
75(34.9) \\
62(28 \cdot 8) \\
30(14.0) \\
4(1.9)\end{array}$ & $\begin{array}{rr}4 & (5 \cdot 9) \\
3 & (4 \cdot 4) \\
16(23 \cdot 5) \\
30(44 \cdot 1) \\
15(22 \cdot 1)\end{array}$ & $\begin{array}{rr}989 & (70 \cdot 0) \\
228 & (16 \cdot 2) \\
112 & (7 \cdot 9) \\
64 & (4 \cdot 5) \\
19 & (1 \cdot 4)\end{array}$ & $\begin{array}{l}48(17 \cdot 0) \\
78(27 \cdot 6) \\
78(27 \cdot 6) \\
60(21 \cdot 2) \\
19(6 \cdot 7)\end{array}$ & $\begin{array}{l}(12 \cdot 9,21 \cdot 6) \\
(22 \cdot 5,32 \cdot 9) \\
(22 \cdot 5,32 \cdot 9) \\
(16 \cdot 7 ; 26 \cdot 1) \\
(4 \cdot 2,10 \cdot 0)\end{array}$ \\
\hline Total & $293(100)$ & $146(100)$ & $690(100)$ & $215(100)$ & $68(100)$ & $1412(100)$ & $283(100)$ & \\
\hline
\end{tabular}

$\mathrm{N}=1480$, 68 missing; percentages have been rounded.

Table 5 Frequency distribution of interference in daily activities in relation to symptom severity in men over the age of 55, North West Thames health region, 1992

\begin{tabular}{|c|c|c|c|c|c|c|c|c|}
\hline \multirow[b]{2}{*}{$\begin{array}{l}\text { Interference in } \\
\text { daily activities }\end{array}$} & \multicolumn{5}{|c|}{ Symptom severity } & \multirow[b]{2}{*}{$\begin{array}{l}\text { Total } \\
\text { No (\%) }\end{array}$} & \multirow[b]{2}{*}{$\begin{array}{l}\text { Moderate E severe } \\
\text { combined } \\
\text { No (\%) }\end{array}$} & \multirow[b]{2}{*}{$\begin{array}{l}(95 \% \text { CI of } \% \\
\text { moderate Eै severe) }\end{array}$} \\
\hline & $\begin{array}{l}\text { None } \\
\text { No (\%) }\end{array}$ & $\begin{array}{l}\text { Very mild } \\
\text { No }(\%)\end{array}$ & $\begin{array}{l}\text { Mild } \\
\text { No (\%) }\end{array}$ & $\begin{array}{l}\text { Moderate } \\
\text { No (\%) }\end{array}$ & $\begin{array}{l}\text { Severe } \\
\text { No (\%) }\end{array}$ & & & \\
\hline $\begin{array}{l}\text { Never } \\
\text { Some of the time } \\
\text { Most of the time } \\
\text { All of the time }\end{array}$ & $\begin{array}{l}284(99 \cdot 0) \\
3(1 \cdot 1) \\
0(0) \\
0(0)\end{array}$ & $\begin{array}{c}145(100) \\
0(0) \\
0(0) \\
0(0)\end{array}$ & $\begin{array}{l}625(92 \cdot 8) \\
57(6 \cdot 9) \\
3(0 \cdot 4) \\
0(0)\end{array}$ & $\begin{array}{c}154(71 \cdot 6) \\
55(25 \cdot 6) \\
6(2 \cdot 8) \\
0(0)\end{array}$ & $\begin{array}{r}24(35 \cdot 8) \\
31(46 \cdot 3) \\
9(13 \cdot 4) \\
3(4 \cdot 5)\end{array}$ & $\begin{array}{r}1232(88 \cdot 1) \\
146(10 \cdot 4) \\
18 \\
3(1 \cdot 3) \\
3(0 \cdot 2)\end{array}$ & $\begin{array}{r}178(63 \cdot 1) \\
86(30 \cdot 5) \\
15(5 \cdot 3) \\
3(1 \cdot 1)\end{array}$ & $\begin{array}{l}(57 \cdot 2,68 \cdot 4) \\
(25 \cdot 2,35 \cdot 9) \\
(3 \cdot 1,8 \cdot 4) \\
(0 \cdot 3,2 \cdot 8)\end{array}$ \\
\hline Total & $287(100)$ & $145(100)$ & $685(100)$ & $215(100)$ & $67(100)$ & $1399(100)$ & $282(100)$ & \\
\hline
\end{tabular}

$\mathrm{N}=1480,81$ missing; percentages have been rounded.

Table 6 Frequency distribution of perception of future in relation to symptom severity in men over the age of 55, North West Thames health region, 1992

\begin{tabular}{|c|c|c|c|c|c|c|c|c|}
\hline \multirow[b]{2}{*}{$\begin{array}{l}\text { Perception of } \\
\text { future }\end{array}$} & \multicolumn{5}{|c|}{ Symptom severity } & \multirow[b]{2}{*}{$\begin{array}{l}\text { Total } \\
\text { No (\%) }\end{array}$} & \multirow[b]{2}{*}{$\begin{array}{l}\text { Moderate Es severe } \\
\text { combined } \\
\text { No (\%) }\end{array}$} & \multirow[b]{2}{*}{$\begin{array}{l}(95 \% \text { CI of } \% \\
\text { moderate } \mathcal{E} \text { severe })\end{array}$} \\
\hline & $\begin{array}{l}\text { None } \\
\text { No (\%) }\end{array}$ & $\begin{array}{l}\text { Very mild } \\
\text { No (\%) }\end{array}$ & $\begin{array}{l}\text { Mild } \\
\text { No (\%) }\end{array}$ & $\begin{array}{l}\text { Moderate } \\
\text { No (\%) }\end{array}$ & $\begin{array}{l}\text { Severe } \\
\text { No (\%) }\end{array}$ & & & \\
\hline $\begin{array}{l}\text { Delighted } \\
\text { Pleased } \\
\text { Not bothered } \\
\text { Unhappy } \\
\text { Terrible }\end{array}$ & $\begin{array}{c}213(75 \cdot 3) \\
59(20 \cdot 9) \\
11(3 \cdot 9) \\
0(0) \\
0(0)\end{array}$ & $\begin{array}{l}85(59 \cdot 9) \\
47(33 \cdot 1) \\
10(7 \cdot 0) \\
0(0) \\
0(0)\end{array}$ & $\begin{array}{c}183(27 \cdot 1) \\
310(45 \cdot 9) \\
155(22 \cdot 9) \\
29(4 \cdot 1) \\
0(0)\end{array}$ & $\begin{aligned} & 3(1 \cdot 4) \\
& 49(22 \cdot 8) \\
& 93(43 \cdot 3) \\
& 65(30 \cdot 2) \\
& 5(2 \cdot 3)\end{aligned}$ & $\begin{array}{r}0(0) \\
3(4 \cdot 4) \\
13(19 \cdot 1) \\
43(63 \cdot 2) \\
9(13 \cdot 2)\end{array}$ & $\begin{array}{r}484(35 \cdot 0) \\
468(33 \cdot 8) \\
282(20 \cdot 4) \\
137(9 \cdot 9) \\
14(1 \cdot 0)\end{array}$ & $\begin{array}{r}3(1 \cdot 1) \\
52(18 \cdot 4) \\
106(37 \cdot 5) \\
108(38 \cdot 2) \\
14(4 \cdot 9)\end{array}$ & $\begin{array}{l}(0 \cdot 3,2 \cdot 8) \\
(14 \cdot 1,23 \cdot 1) \\
(31 \cdot 9,43 \cdot 0) \\
(32 \cdot 5,43 \cdot 8) \\
(2 \cdot 8,7 \cdot 9)\end{array}$ \\
\hline Total & $283(100)$ & $142(100)$ & $677(100)$ & $215(100)$ & $68(100)$ & $1385(100)$ & $283(100)$ & \\
\hline
\end{tabular}

$\mathrm{N}=1480,95$ missing; percentages have been rounded.

the different numbers of men at risk of having surgery, the probability of having surgery when in each age group was calculated by dividing the number of men who had surgery when in each age group by the number of men that had reached that age group (table 7). The probability of having surgery when under 50 years of age was only $0.1 \%$ and increased to $8 \%$ in the age group 75 to 79 years. This is equivalent to a doubling in the probability of having surgery every five years. Because there are fewer men in older age groups, this gives a different picture to that seen in urological practice. Almost half $(45.7 \%)$ the men who had undergone surgery were aged between 60 and 69.

Of the $156(6 \%)$ men who reported a previous episode of acute retention, only $38.5 \%$ had undergone surgery (table 8). Altogether $8 \%$ of men reported a previous urinary tract infection. When asked about urinary in- continence, $7 \cdot 5 \%$ leaked enough urine to be embarrassed, and $0 \cdot 8 \%$ needed to wear pads.

\section{SUMMARY}

The current pattern of urinary symptoms in men aged 55 and over and the urological response to them is best illustrated by combining the data on the prevalence of men with a history of prostate surgery (table 7) and the prevalence of urinary symptoms (table 3). Figure 3 shows the proportions of men in each age group in each of the following states: (a) no, very mild, or mild symptoms and no previous surgery; (b) moderate/severe symptoms but no previous surgery; (c) previous surgery with no current moderate/severe symptoms; and (d) previous surgery and current symptoms. The percentage of men with either moderate or severe symptoms or a history of previous prostate surgery, or both, increased from $17 \%$ at age 57 years 
Table 7 Experience of prostate surgery in men over the age of 55, North West Thames health region, 1992

\begin{tabular}{|c|c|c|c|c|c|}
\hline $\begin{array}{l}\text { Age group } \\
\text { (y) }\end{array}$ & $\begin{array}{l}\text { No of sample } \\
\text { reached or exceeded } \\
\text { age group }\end{array}$ & $\begin{array}{l}\text { No (\%) having surgery } \\
\text { within age category }\end{array}$ & $\begin{array}{l}\% \text { probability of } \\
\text { having surgery } \\
\text { when in age group }\end{array}$ & $\begin{array}{l}\text { No (\%) with } \\
\text { previous surgery in } \\
\text { current age group }\end{array}$ & $\begin{array}{l}\text { Current } \% \text { probability } \\
\text { of having had previous } \\
\text { surgery by age }\end{array}$ \\
\hline $\begin{array}{l}<50 \\
50-54 \\
55-59 \\
60-64 \\
65-69 \\
70-74 \\
75-79 \\
80-84 \\
85+\end{array}$ & $\begin{array}{r}1443 \\
1443 \\
1443 \\
1168 \\
846 \\
548 \\
312 \\
155 \\
51\end{array}$ & $\begin{array}{rr}2 & (1 \cdot 3) \\
8 & (5 \cdot 2) \\
17 & (11 \cdot 1) \\
34 & (22 \cdot 2) \\
36 & (23 \cdot 5) \\
21 & (13 \cdot 7) \\
25 & (16 \cdot 3) \\
8 & (5 \cdot 2) \\
2 & (1 \cdot 3)\end{array}$ & $\begin{array}{l}0 \cdot 1 \\
0 \cdot 6 \\
1 \cdot 2 \\
2.9 \\
4 \cdot 3 \\
3 \cdot 8 \\
8 \cdot 0 \\
5 \cdot 2 \\
3.9\end{array}$ & $\begin{array}{rr}7 & (4 \cdot 3) \\
17 & (10 \cdot 4) \\
31 & (18 \cdot 9) \\
32 & (19 \cdot 5) \\
34(20 \cdot 7) \\
26(15 \cdot 9) \\
17(10 \cdot 4)\end{array}$ & $\begin{array}{r}0.5 \\
1.5 \\
3.7 \\
5.8 \\
10.9 \\
16.8 \\
33.3\end{array}$ \\
\hline Total & & $153(100)$ & & $164(100)$ & \\
\hline
\end{tabular}

$\mathrm{N}=169$ (with previous surgery); missing age at previous surgery $=16$, missing current age $=5$.

to $38 \%$ at age 81 . The percentage of men with moderate/severe symptoms who have not had prostate surgery increases until the age of 73 and then seems to decrease. Of men who have had prostatectomy, the percentage with recurrence or persistence of moderate or severe symptoms seems to remain relatively constant across the age range, at about $30 \%$.

\section{Discussion}

This study has described the prevalence and severity of urinary symptoms in British men aged 55 and over. Although most men report no urinary symptoms, $20 \%$ reported moderate or severe symptoms. Of these, only $28 \%$ found their symptoms a medium or big problem. Thirty seven per cent experienced interference with their daily activities at least some of the time, and $43 \%$ would be unhappy at the prospect of a future with their symptoms continuing at their current level.

Before any conclusions may be drawn, the limitations of this survey should be considered. Men in the 55 to 59 year age group were under-represented compared with the general population, although comparison of the mean

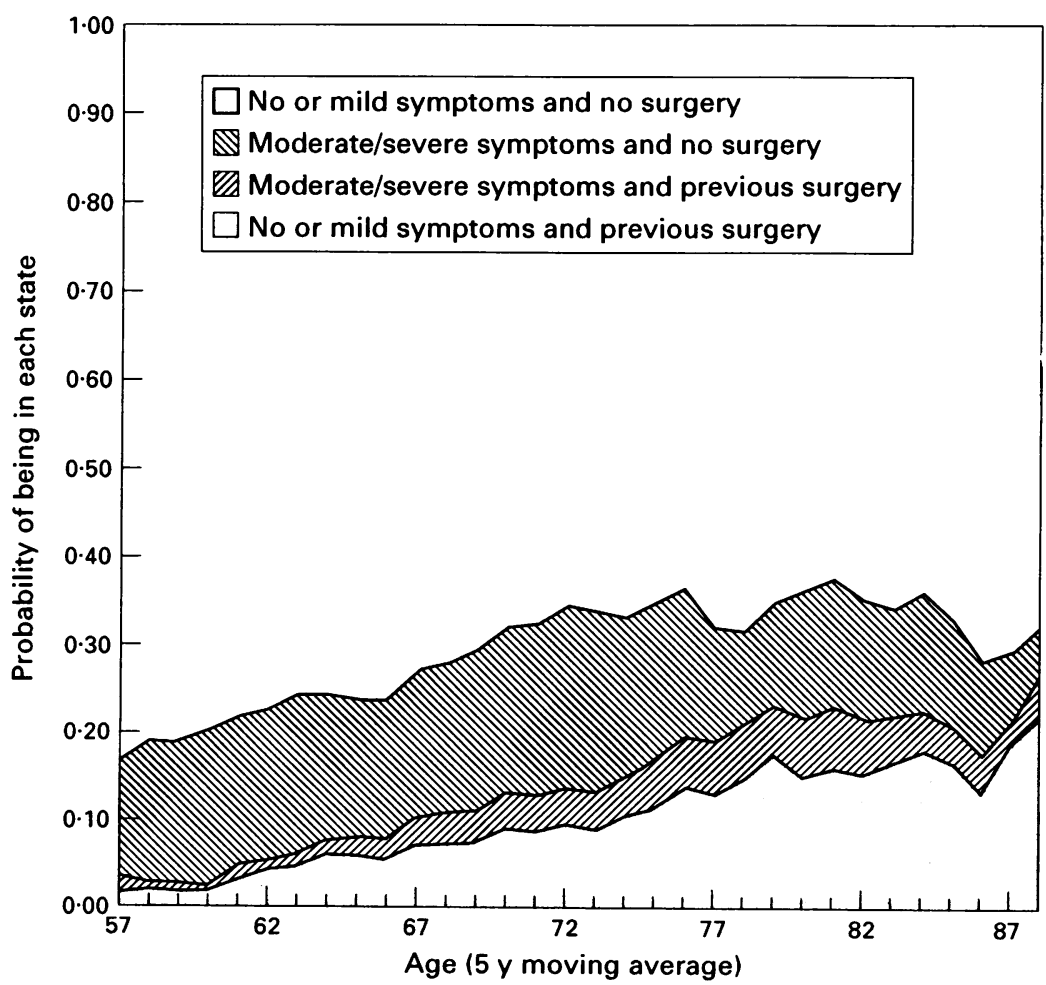

Figure 3 Age specific probabilities of moderate/severe symptoms and previous prostate surgery in men aged 55 years and over, North West Thames health region, 1992. age of responders and non-responders suggests that this may have been due to characteristics of the practices studied rather than a difference in response rate.

Secondly, those who do not respond to surveys may differ in some way from those who do. From the examination of case notes we found that $8 \%$ of men who did not respond had died, moved, or had no general practice medical records. This suggests that our true response rate may have been as high as $80 \%$. Non-responders did not differ from responders in terms of their history of urinary symptoms as recorded in the general practice records but they were less likely to have had previous prostate surgery.

Thirdly, the way the questions were phrased could bias the results. The AUA symptom index for the symptoms of benign prostate hyperplasia has been extensively tested and has been shown to be internally consistent and have good test-retest reliability, as judged by Pearson correlation coefficients. ${ }^{11}$ Symptom severity categories were derived from cut off points used in a previous study. The use of different cut offs would have important implications for the numbers of individuals in each category. For example, we defined moderate or severe symptoms as a symptom index of greater than 9 , giving a prevalence in the male population aged 55 and over of 204 per 1000 . Reduction of the threshold to 8 would result in a prevalence of 227 per 1000; a threshold of 11 would result in a prevalence of 170 per 1000 .

Our survey measured the felt need for treatment rather than the normative need. The clinical decision to offer treatment is based on a combination of urinary symptoms and the results of urological investigation. Assessment of normative need is complicated by the absence of an accepted definition of benign prostate hyperplasia. Currently, there is a debate in the urological literature about the importance of each. Several studies have shown a poor correlation between symptoms and objective urological measures such as flow rates and residual volume. ${ }^{15-18}$ Given that most surgery

Table 8 Distribution of previous surgery in relation to acute urinary retention in men aged 55 and over, North West Thames region, 1992

\begin{tabular}{|c|c|c|c|}
\hline \multirow[b]{2}{*}{ Retention } & \multicolumn{2}{|c|}{ Previous surgery } & \multirow[b]{2}{*}{$\begin{array}{l}\text { Total } \\
\text { No (\%) }\end{array}$} \\
\hline & $\begin{array}{l}\text { Yes } \\
\text { No (\%) }\end{array}$ & $\begin{array}{l}\text { No } \\
\text { No (\%) }\end{array}$ & \\
\hline $\begin{array}{l}\text { Yes } \\
\text { No }\end{array}$ & $\begin{array}{l}60(38 \cdot 5) \\
24(1.9)\end{array}$ & $\begin{array}{r}96(61 \cdot 5) \\
1239(98 \cdot 1)\end{array}$ & $\begin{array}{r}156(100) \\
1263(100)\end{array}$ \\
\hline Total & $84 \quad(5.9)$ & $1335(94 \cdot 1)$ & $1419(100)$ \\
\hline
\end{tabular}


is carried out to improve a man's quality of life, we therefore believe that the presence of urinary symptoms is an essential, though not the only, factor that should be measured when assigning the need for surgery in the population.

It has been suggested that there is a large proportion of men in the British population with undiagnosed but symptomatic prostatism. ${ }^{7}$ Our study supports this view. The only other study on the prevalence of urinary symptoms in men in the UK has been reported by Garraway et al. They reported a prevalence in men aged $40-79$ years of 104 per $1000 .{ }^{19}$ These figures refer to men with a symptom score of at least 11 out of a possible 48 points (eight symptoms each with a maximum score of six). If we were to use an equivalent cut-off point with our data, 7 out of 30 , we would produce a prevalence of 292 per 1000 . However, some important methodological differences between the two studies remain. In the study by Garraway et al, the men were younger (over 50\% were under 55 years), 9\% of men in the study population were excluded, and the response rate was lower (only $64 \%{ }^{19}$ compared with $78 \%$ ). All of these might explain why they obtained a lower estimate of prevalence than we did. These factors could therefore reconcile our results with theirs.

The finding that $61.5 \%$ of men with a history of acute retention had not undergone surgery indicates that the view that this is an almost absolute indication for surgery ${ }^{20}$ is no longer held. This finding is consistent with the views of a consensus panel on the appropriate indications for prostatectomy that was held recently. ${ }^{21}$

These results and evidence from other studies suggest that prostatism begins to develop in some men under the age of 50 . Although we based our sample on evidence that prostatectomy was almost never performed on men under the age of 55 , the relatively high prevalence of moderate or severe symptoms among men in the 55 to 59 age group indicates that future studies should include younger men. This is consistent with the population based survey by Garraway et al that described the onset of urinary symptoms among men in their $40 \mathrm{~s}^{7}$ and a review of necropsy data by Berry et al suggesting that the first changes in prostatic weight appear in men as young as under $30 .^{22}$ From the age of 55 until the early 70 s, the percentage of men with moderate or severe symptoms who have not had surgery increases slowly from $15 \%$ to $20 \%$, decreasing thereafter. A few individuals have surgery under 50 , but the probability of surgery only exceeds $1 \%$ in the 55 to 59 age group. Thereafter it increases steadily. This leads to a progressive increase in the number of men who have had surgery by the age of 85 . Of those who have had surgery, the proportion who have residual or recurring symptoms is roughly constant. The figure of about a third in this study is higher than that found in two cohort studies of men undergoing surgery ${ }^{1323}$ but both followed up patients for only one year. Some of the men in our survey had surgery up to 10 years previously.

These results suggest that prostatism, shown by the prevalence of either urinary symptoms or a past history of prostatic surgery, increases steadily throughout middle and old age, with the first signs appearing under the age of 55 and with almost $40 \%$ of men having been affected by the age of 80 . After 80 , the prevalence of prostatism does not increase further, and may actually decrease. These findings may occur by chance because there were only 29 men over the age of 80 in our sample with moderate or severe symptoms, but if the suggested decrease is true, there are three possible explanations. The first is that some cases of benign prostate hyperplasia resolve spontaneously. This has been suggested by other authors, although there is no strong empirical supporting evidence. ${ }^{24}$ Secondly, most of those men who are going to suffer from benign prostate hyperplasia begin to do so by the time they reach 80 , and the population contains subgroups with varying susceptibilities to the disease. Some support for this hypothesis comes from a review of series of necropsy data that suggested that at least $10 \%$ of men have no histological evidence of benign prostate hyperplasia by the time they reach the ninth decade. ${ }^{22}$ The third possibility is that men with benign prostate hyperplasia have a reduced life expectancy, leading to selection out of the population in this age group. If the last of these is true, it could be due to either the effects of the disease or the complications of treatment. This explanation is consistent with the results of the study by Wennberg et al that suggested that transurethal prostatectomy was associated with an increase in mortality compared with men not undergoing surgery. ${ }^{25}$ If any of these suggestions, or a combination thereof, are true there are important implications for urology research and practice, especially as new treatments designed to prevent the development of benign prostatic hypertrophy becomes available. For example, it would be useful to compare the characteristics, such as differences in androgen responsiveness, of those men who will and will not suffer from benign prostate hyperplasia.

Although $20.4 \%$ of men have moderate or severe symptoms, this does not reflect the degree of concern that they express. Only 5.9\% of men report that their symptoms are a medium or big problem and $1.5 \%$ report that they interfere with their daily activities all or most of the time. In contrast, $10.9 \%$ feel unhappy or terrible about the prospect of a future with their current level of symptoms, indicating a difference between the extent to which men are affected at present and how they would like to be in the future. A possible explanation for this is that men are able to cope with their existing level of symptoms but feel that they will be unable to do so in the future as they become older and more infirm. This is supported by evidence from a study of women suffering from urinary incontinence. ${ }^{26}$

How will the results of this study be used? A second survey of those men who reported moderate or severe symptoms has been undertaken. This will report on the ways that their symptoms affect their health status and 
whether or not they would choose to have surgery. When combined with information on clinicians' views of appropriateness and patient preference for treatment, these data will provide estimates both of the normative need for treatment and demand in the population and inform planning of the provision of urological services.

This work was funded by the Locally Organized Research of the North West Thames Regional Health Authority. We are grateful to the collaborating general practitioners who participated in the study and to all of the men who completed the questionnaire.

1 Gofin R. The health status of elderly men: A community study. Public Health 1982;96:345-54.

2 Yesalis CE et al. Health status of the rural elderly according to farm work history; The Iowa rural health study. Arch Environ Health 1985;40:245-53.

3 Fernandez E, Porta M, Alonso J, Anto JM. Epidemiology of prostatic disorders in the city of Barcelona. Int $\mathcal{f}$ Epidemiol 1992;21 (5):959-65.

4 Diokno AC, Brown MB, Goldstein N, Herzog AR. Epidemiology of bladder emptying symptoms in elderly men

5 Steyn $M$. Just old age? A study of prostatism in general practice. Fam Pract 1988;5(3):193-5.

6 Britton JP, Dowell AC, Whelan P. Prevalence of urinary symptoms in men over the age of $60 . \mathrm{Br} \mathcal{F}$ Urol 1990;66 $175-6$.

7 Garraway WN, Collins GN, Lee RJ. High prevalence of benign prostatic hypertrophy in the community. Lance 1991;338:469-71.

8 Chute CG, Panser LA, Girman CJ, Oesterling JE, Guess HA, Jacobsen SJ, Lieber MM. The prevalence of prostatism: A population-based survey of urinary symptoms. f Urol 1993;150:85-9.

9 Holgersen-Beier, R, Bruun J. Voiding pattern of men 60 to 70 years old: Population study in an urban population. $\mathcal{F}$ Urol 1990;143:531-2.

10 Doll HA, Black NA, McPherson K, Flood AB, Williams GB, Smith JC. Mortality, morbidity, and complications following transurethal resection of the prostate for benign following transurethal resection of the prostate for

11 Barry MJ, Fowler FJ Jr, O'Leary MP. Bruskewitz RC, Holtgrewe HL, Mebust WK, Cockett ATK. The American
Urological Association symptom index for benign prostatic hyperplasia. F Urol 1992;158:1549-75.

12 Office of Populations Censuses and Surveys (OPCS), Department of Health. 1991 Census, County Monitor (CEN 91 CM 17/2) London: OPCS, 1992.

13 Flood AB, Black NA, McPherson K, Smith J, Williams $\mathrm{G}$. Assessing symptom improvement following elective prostatectomy for benign prostatic hyperplasia. Arch In Med 1992;152:1507-12.

14 Fleiss JL. Statistical methods for rates and proportions. 2nd ed. New York: John Wiley, 1981

15 Andersen JT, Nordling J, Walter S, Prostatism I. The correlation between symptoms, cystometric and urodynamic findings. Scand f Urol Nephrol 1979;13:229-36.

16 Jensen KME. Clinical evaluation of routine urodynamic investigations in prostatism. Neurorology and Urodynamics 1989;8:545-78.

17 Neal DA, Styles RA, Powell PH, Thong J, Ramsden PD. Relationship between voiding pressures, symptoms and urodynamic findings in 253 men undergoing prostatectomy. $\mathrm{Br} \mathcal{F}$ Urol 1987;60:554-9.

18 Barry MJ, Cockett ATK, Holtgrewe HL, McConnell JD, Sihelnik SA, Winfield HN. Relationship of symptoms of prostatism to commonly used physiological and anaprostatism to commonly used physiological and ana-
tomical measures of the severity of benign prostatic hyperplasia. F Urol 1993;150:351-8.

19 Garraway WM, McKelvie GB, Russell EBAW et al. Impact of previously unrecognized benign prostatic hyperplasia on the daily activities of middle-aged and elderly men. $\mathrm{Br}$ f Gen Pract 19

20 Blandy JP. The indications for prostatectomy. Urol Int 1978; 33:159-70.

21 Hunter DJW, McKee CM, Sanderson CFB, Black NA. Appropriate indications for prostatectomy - results of a consensus panel. $\mathcal{F}$ Epidemiol Community Health 1994;48: 58-64

22 Berry SJ, Coffet DS, Walsh PC, Ewing LL. The development of benign prostatic hypertrophy with age. $7 \mathrm{Uml} 1984$ 132:474-9.

23 Fowler FJ, Wennberg JE, Timoty RP, Barry MJ, Mulley AG, Hanley D. Symptom status and quality of life following prostatectomy. $\mathscr{f} A M A$ 1988;259:3018-22.

24 Burkitt R. Benign prostatic hyperplasia. BMF 1993;307: 201.

25 Wennberg JE, Roos NM, Sola L, Schori A, Jaffe R. Use of claims data systems to evaluate health care outcomes. Mortality and reope

26 Hampstead Health Authority. Community continence service: A critical review. London: Hampstead Health Authority, 1987 